\title{
The Nature and Extent of Psychosocial Problems Facing Orphaned Pupils In Public Pre-Schools in Nakuru Municipality, Kenya
}

\author{
Maina Jecinta Wanjiru \\ Master of Education in Early Childhood Education in the Department of Educational Communication and Technology of University of \\ Nairobi
}

\begin{abstract}
Healthy child development depends, to a great extent, on the continuity of social relationships and development of a sense of competence. Like adults, children are grieved by the loss of their parents. They suffer from anxiety and fear during the years of parental illness followed by grief and trauma after the death of parent(s). This study determines nature and extent of psychosocial problems facing orphaned pupils in public pre-schools in Nakuru municipality, Kenya. Data was analyzed using descriptive statistics. Descriptive statistics (percentage and frequencies) presented in tables and pie charts were used to summarize data and to describe the characteristics of the sample. $20 \%$ of 240 orphans in public preschools was used to get a sample of 48 pupils. A big percentage 22 (88\%) felt isolated. Most of the orphaned preschool pupils had not been debriefed. Orphaned preschool children had psychosocial problems which needed attention to enable them to adjust.
\end{abstract}

Keywords: psychosocial problems, orphans, pupils, Nakuru, Kenya

\section{Introduction}

Healthy child development depends, to a great extent, on the continuity of social relationships and development of a sense of competence. The loss of parents can undermine the fundamental human attachments essential for normal family life and child development (Sengendo and Nambi, 1997). Like adults, children are grieved by the loss of their parents. They suffer from anxiety and fear during the years of parental illness followed by grief and trauma after the death of parent(s). However, unlike adults, children often do not feel the full impact of the loss as they may not immediately understand the finality of death. This prevents them from going through the grieving process which is necessary to recover from the loss (Phiri and Webb, 2000; Brodzinsky, Gromly and Ambrown, 1986). Children therefore are at risk of growing up with unresolved negative emotions which are often expressed with anger and depression. Adults may also experience negative emotions in time of emotional support that enable them to control their anger and depression (Brodzinsky et al., 1986). Unfortunately, little attention is given to the children's emotions. Children are not given the required support and encouragement to express their emotions nor are they guided to deal with them (Sengendo and Nambi, 1997). The death of parent(s) also introduces a major social change in the life of a child. The social changes can easily affect not only the physical but also the psychological wellbeing of the children. This can be very stressful as they pose new demands and constraints to the child's life. It is feared that many children may find it difficult to adapt to the new changes (Sengendo and Nambi, 1997). It is argued that it is not the social change itself that may cause psychological problems; rather it is failure of the individual to adapt to social changes. Like bereavement, social change and the resultant need to adapt to it may create stress which may be shown in symptoms of confusion, anxiety, depression and behavioural disorders. The same symptoms may cause learning problems. Children who are frustrated, fearful and depressed may fail to concentrate in class and thus perform poorly. The social and psychological problems, if not well managed, are likely to negatively affect the learning process and behaviour of children. This is in addition to the other social, economic, personal and academic challenges that all pupil face at school and at home. Failure by the school and whole systems to recognize these symptoms and address them will aggravate the child's psychological problems.

According to NASCOP (1981), the situation is more complicated when the cause of the parental death is HIV/AIDS due to the associated social stigmatization. Though levels of HIV/AIDS are lower in children than adults, children remain the most highly vulnerable. The pandemic has turned millions of children into orphans in the 43 countries hardest hit by AIDS (UNAIDS, 2002:2001). Africa is home to $90 \%$ of the children orphaned by AIDS. As the number of orphaned children continues to increase, their psychological needs are being recognized as being equal in importance to the needs relating to subsistence, health and education (Cook, Fritz and Mwonya, cited in Singal and Howard, 2003). The orphans must deal with a lot more than the death of their parent(s); they must cope with the psychological impact, "common reactions of children of the death of a parent include: depression, hopelessness, loneliness, anger, confusion, helplessness, anxiety and fear of being alone" (Phiri and Webb, 2000). These feelings are constant and even terminology used to describe their effect of HIV/AIDS on children creates feelings of pain and resentfulness. A USAID report to Congress suggests that singling out children orphaned by AIDS exacerbated the stigma attached to the disease (Stein, 2003; Phiri and Webb, 2002). All in all, the number of orphans is increasing while there are a few support systems or networks for them outside the family which compromises their future (Gobley and Cosdagh, 2004). 


\section{International Journal of Science and Research (IJSR) \\ ISSN (Online): 2319-7064 \\ Index Copernicus Value (2013): 6.14 | Impact Factor (2015): 6.391}

\section{Sampling, Data Collection}

Sampling is the act, process or technique of selecting sample or a representative part of a population for the purpose of determining parameters of characteristics of the whole population (Gay, 1981). For descriptive studies $20 \%$ of the population is enough for smaller samples $20 \%$ of 240 orphans in public preschools was used to get a sample of 48 pupils. All the five education zones in Nakuru Municipality were involved in the study.

From each of the five zones, simple random sampling was used to select six (6) public preschools. Pieces of paper with name of preschools in each zone were put in a bag shuffled then drawing from it without replacement. Lastly, purposive sampling was used to select one teacher counsellor for each of the sampled and the head teacher of the institution. The above preschool sampling procedure gave the following respondents: 30 teacher counselors, 30 head teachers and 48 pupils who formed the final sample for this study.

Permission was also sought from the head teachers of the pre schools involved in the study. The researcher then visited the selected pre schools before actual data collection for familiarization and acquaintance with the head teachers about the purpose of the intended study and booked appointments for data collection.

\subsection{Data Analysis}

Data was analyzed using descriptive statistics. Descriptive statistics (percentage and frequencies) presented in tables and pie charts were used to summarize data and to describe the characteristics of the sample. Inferential statistics technique of Pearson Coefficient was used to establish correlation. All tests were done at 0.01 level of significance.

\section{Research Findings}

Table shows persons staying with the orphaned pupils. Out of 48 respondents 23 (47.9\%) stayed with their grandparents, $10(20.8 \%)$ lived with their mothers, $6(12.5 \%)$ with their relatives, $5(10.4 \%)$ with their fathers while $4(8.3 \%)$ stayed with well wishers. The immediate psychosocial adjustment depends on the persons that the orphan stay with. Most orphans lived with their relatives apart from one of the parents in the study. This may have increased their social and psychosocial problems that affect their normal development as a result of anxiety, fear, grief and trauma following the death of their parents.

Table: Social and psychological problems faced by orphans (observed by Teacher counselors). N-28

\begin{tabular}{|l|l|l|}
\hline & Frequency & Percentage \\
\hline Relatives & 6 & 12.5 \\
\hline Brother or sister & 0 & 0 \\
\hline Well wishers & 4 & 8.3 \\
\hline Grand parents & 2 & 47.9 \\
& 3 & \\
\hline Father & 5 & 10.4 \\
\hline Mother & 10 & 20.8 \\
\hline Total & 4 & 100 \\
\hline
\end{tabular}

\begin{tabular}{|c|c|c|c|c|c|c|}
\hline Problems & YES & & NO & & TOTAL & \\
\hline & Frequency & $\%$ & Frequency & $\%$ & N & $\%$ \\
\hline Social & & & & & & \\
\hline Isolation & 22 & 88 & 3 & 12 & 25 & 100 \\
\hline Aggression & 12 & 54.5 & 10 & 45.5 & 22 & 100 \\
\hline Uncooperative & 9 & 37.5 & 15 & 62.5 & 24 & 100 \\
\hline Truancy & 15 & 75 & 5 & 25 & 20 & 100 \\
\hline Psychological & & & & & & \\
\hline Lack of concentration & 24 & $92.3 \%$ & 2 & $7.7 \%$ & 31 & 100 \\
\hline Sleep in class & 14 & $63.6 \%$ & 8 & $36.4 \%$ & 22 & 100 \\
\hline Cry when asked questions & 24 & $96 \%$ & 1 & $4 \%$ & 25 & 100 \\
\hline
\end{tabular}

The items from the teacher counselor were used to elicit information on orphans behaviour. A majority of the pupils $24(96 \%)$ cry when asked questions. A big percentage 22 (88\%) felt isolated. From this information there is evidence that most of the orphans isolate themselves. This could be attributed to the status of the orphans. This is in line with Erickson's theory which asserts that unsuccessful psychosocial crisis stage develops a tendency towards a negative opposing force which becomes behaviour of isolation, aggression, anger, depression and low self esteem. This can also be confirmed from table 9 which shows aggressiveness 12 (54.5\%), uncooperative 9(37.5\%) and 15(75\%) indicated truancy.

\subsection{Summary of Major Findings}

The main purpose of this study was to find out the role of guidance and counseling in addressing psychosocial needs of orphaned pupils in public schools in Nakuru Municipality. The findings were:

1) Most of the orphaned preschool pupils had not been debriefed.

2) Majority of the orphaned pupils had not interacted well socially.

3) Results also indicated that the orphaned pupils do not concentrate in class, cry when asked questions and many are not attentive. There is little psychosocial adjustment.

4) There is lack of facilities and financial support for guidance and counselling. 


\section{Conclusion and Recommendations}

Based on the major findings, the study made the following conclusions:

1) Orphaned preschool children had psychosocial problems which needed attention to enable them to adjust.

2) Majority of preschool teacher counselors were not professionally qualified to handle complex issues faced by the orphaned pupils.

\section{References}

[1] Brodzinsky, D.M. and Ambron, S.R. (1986).Life span human Development (3rd Ed).New York: CBS College Publishing.

[2] Cook, A.S., Fritz, J.J. \& Mwonya, R. (2003). Understanding the psychological and emotional needs of AIDS orphans in Africa. Ohio: Ohio University Press

[3] Gay, L.R (1981). Student guide for educational Research compentencies for analysis and application. Columbus: Charles E. Merill Publishing Company.

[4] Gobey, F.\&Casdagh (2004). Grief, Bereavement and Change, Guidance for Teachers in PSHE. London. Heinman Oxford

[5] Sengendo, J. \& Nambi, 1997. The Psychological Effects of Orphanhood. A study of Orphans in Rakia District. In Health Transition Review, Supplement to Vol.7 pp. 105124

[6] Stein, J.O (2003). Sorrow Makers Children of US All: A literature Review on Pycho-social impact HIV/AIDs on children. Cape town: Centre for Social Science Research.

[7] Phiri, S.\& Webb, D. (2000); the Impacts of HIV/AIDS on Orphans and Programmes and policy Responses.

\section{Author Profile}

Maina Jecinta Wanjiru, obtained Masters in education in early childhood education in the department of educational communication and technology of University of Nairobi, Kenya. She is currently working as a teacher with the Teachers Service Commission Kenya and as a part time lecturer at St. Paul's University Nakuru Campus. 